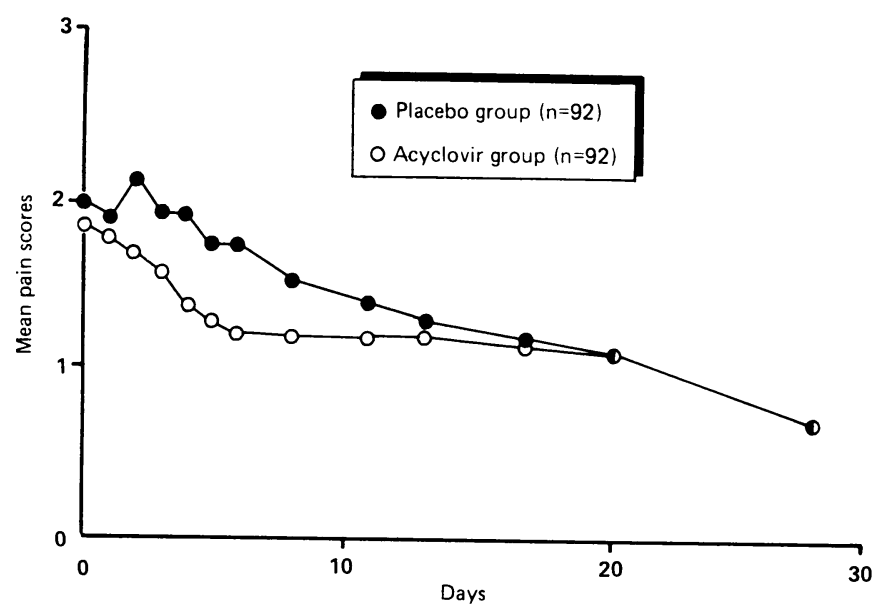

Plot of average daily pain scores (0-3 scale) in the two treatment groups. (Number of patients in each group were those with complete set of observations.)

The single dermatome most commonly affected in herpes zoster is the ophthalmic division of the trigeminal nerve. Though trends in favour of the treatment group were seen with regard to reduction in pain (day 6 to day 0 ), the changes did not reach statistical significance $(p=0 \cdot 14)$. This may relate to the fact that the number of patients with ophthalmic zoster was relatively small-53 (21 acyclovir, 32 placebo)-and 24 (45\%) of these had a rash of 48 to 72 hours' duration before entry. The numbers were too small to analyse according to time of onset of rash.
This study has shown that oral acyclovir may modify the course of acute herpes zoster and reduce pain. This benefit was most pronounced in patients who began treatment within 48 hours of the onset of rash. In addition, pain relief was particularly noticeable in those with the most severe pain. Acyclovir $800 \mathrm{mg}$ five times daily appears to be a suitable regimen, though better absorbed preparations should allow lower dosage regimens to be employed. It appears that a seven day course is preferable to a five day course of treatment. The effect of this regimen on postherpetic neuralgia is not known, but studies are continuing.

Collaborators in the study were: C D Care, research nurse, Lodge Moor Hospital, Sheffield 10; J A Innes, consultant, department of communicable and tropical diseases, and $\mathrm{P} \mathrm{H}$ Ogan, research nurse, East Birmingham Hospital, Bordesley Green East, Birmingham; E M Webb, research nurse, Southampton Eye Hospital, Southampton; and E A Hickmott, D A Jones, and A M Gilbert, Wellcome Research Laboratories, Beckenham, Kent.

\section{References}

1 Bean B, Braun C, Balfour HH. Acyclovir therapy for acute herpes zoster. Lancet 1982;ii:118-21.

2 Peterslund NA, Seyer-Hansen U, Ipsen J, Esmann V, Schonheyder H, Juhl H. Acyclovir in herpes zoster. Lancet 1981;ii:827-30.

3 McGill J, McDonald DR, Fall C, McKendrick GDW, Copplestone A. Intravenous acyclovir in acute herpes zoster infections. Fournal of Infection 1983;6:157-61.

4 McGill J. Topical acyclovir in herpes zoster ocular involvement. Br f Ophthalmol 1981;65:542-5.

5 Peterslund NA, Esmann V, Ipsen J, Christensen KD, Petersen CM. Oral and intravenous acyclovir are equally effective in herpes zoster. $\mathcal{F}$ Antimicrob Chemother 1984;14:185-9.

6 McKendrick MW, Care C, Burke C, Hickmott E, McKendrick GDW. Oral acyclovir in herpes zoster. F Antimicrob Chemother 1984;14:661-5.

7 Keczkes K, Basheer AM. Do corticosteroids prevent post-herpetic neuralgia? Br $\mathcal{f}$ Dermatol 1980;102:551-5.

8 Elliott FA. Treatment of herpes zoster with high doses of prednisone. Lancet 1964;ii:610-1.

(Accepted 24 September 1986)

\title{
Chemoprophylaxis with oral amoxycillin against bacterial endocarditis: When should second doses be administered after dentistry?
}

\author{
C R KUMANA， K K CHAU， P Y CHAU， M KOU， I LAUDER
}

\begin{abstract}
The adequacy of serum bactericidal activity after oral amoxycillin given as prophylaxis against infective endocarditis was studied using a double blind randomised protocol in healthy volunteers having dentistry. One hour before their procedure 38 patients received $3 \mathrm{~g}$ amoxycillin syrup and 12 received matching placebo. Venous blood samples were drawn before and one and nine hours after dosing and serum amoxycillin concentrations determined using a standard bioassay. Samples containing amoxycillin had inhibitory titres measured against two reference isolates of viridans streptococci known to have caused infective endocarditis. The susceptibility to amoxycillin of one strain was high
\end{abstract}

University of Hong Kong

C R KUMANA, BSC, FRCP, reader in medicine

$\mathrm{K}$ K CHAU, MDS, FRACDS, reader in oral surgery and oral medicine

P Y CHAU, MB, MRCPATH, reader in microbiology

$M$ KOU, SRN, senior research assistant, departments of medicine and oral surgery and oral medicine

I LAUDER, MSC, PHD, senior lecturer in statistics

Correspondence to: Dr C R Kumana, University Department of Medicine, Queen Mary Hospital, Hong Kong. and the other low, respective minimal bactericidal and inhibitory concentrations being 0.08 and $0.04 \mu \mathrm{mol} / 1(0.03$ and $0.015 \mu \mathrm{g} / \mathrm{ml})$ and 2.74 and $1.37 \mu \mathrm{mol} / 1$ ( 1 and $0.5 \mu \mathrm{g} / \mathrm{ml}$ ).

Amoxycillin was detected in only post-treatment samples of patients given the active drug. There were no significant correlations between one or nine hour drug concentrations and age or physical characteristics, nor was there any relation to preceding food consumption. Correlations between drug concentrations at one and nine hours were weak $(r=0.34 ; p<0.05)$, but between corresponding drug concentrations and serum inhibitory titres there were consistent correlations $(r=0.46-0.48 ; p<0.005)$. Against the low susceptibility reference isolate bactericidal amoxycillin concentrations were encountered in only 20 of the 38 nine hour samples (95\% confidence limits $34 \%$ and $66 \%$ ).

When repeat doses of amoxycillin are indicated after dentistry they should be given about four hours later, not eight hours later as commonly practised.

\section{Introduction}

A widely accepted and simple regimen of antimicrobial prophylaxis against bacterial endocarditis for patients with susceptible cardiovascular lesions having dentistry consists of giving amoxycillin $3 \mathrm{~g}$ 
by mouth one hour before the procedure and preferably repeating the dose eight to nine hours after the procedure. ${ }^{12}$ This regimen appeared to be particularly attractive for an area such as Hong Kong, where dental services are neither free nor well developed and some patients live on relatively isolated islands. Most cases of infective endocarditis attributable to bacteria originating in the mouth are due to viridans streptococci. ${ }^{3}$ We therefore designed a placebo controlled trial to answer the following question in otherwise healthy patients having dental extractions or minor oral surgery under local anaesthesia: Does amoxycillin $3 \mathrm{~g}$ by mouth one hour before the procedure provide bactericidal activity in the serum for up to eight hours after the procedure against isolates of viridans streptococci known to have caused infective endocarditis?

\section{Patients and methods}

Fifty otherwise healthy subjects ( 25 men) with a mean age of 25 were recruited from patients having dental extractions or minor oral surgery under local anaesthesia. Criteria for exclusion were the presence of cardiac lesions (lest the patient was assigned to receive placebo), a history of allergy to any penicillin, pregnancy, or antimicrobial treatment within the past 48 hours or up to eight hours later. Using a double blind randomised protocol, 38 patients were given $3 \mathrm{~g}$ amoxycillin in $30 \mathrm{ml}$ of strawberry flavoured syrup and 12 a matching placebo. Patients took the medications one hour before the estimated time of dentistry. Venous blood samples $(20 \mathrm{ml})$ were drawn before treatment and one and nine hours after treatment. All the patients gave written, informed consent to the study and the whole project was approved by institutional ethics committees.

Each blood sample was collected and processed under sterile conditions; samples were allowed to clot, refrigerated, and the serum separated and stored at $-20^{\circ} \mathrm{C}$ for analysis within two weeks. Samples were thawed in batches and amoxycillin concentrations determined by disc plate bioassay by a trained technician who was unaware of each patient's medication. Fifteen stored isolates of viridans streptococci from confirmed cases of infective endocarditis managed at Queen Mary Hospital were subcultured and the minimal inhibitory concentration of amoxycillin against each strain determined (see figure) by an agar dilution method. From among these, one with an amoxycillin minimal inhibitory concentration of $0.04 \mu \mathrm{mol} / 1(0.015$ $\mu \mathrm{g} / \mathrm{ml})$ and minimal bactericidal concentration of $0.08 \mu \mathrm{mol} / 1(0.03 \mu \mathrm{g} / \mathrm{ml})$ was selected as a high susceptibility reference isolate and one with a minimal inhibitory concentration of $1.37 \mu \mathrm{mol} / 1(0.5 \mu \mathrm{g} / \mathrm{ml})$ and minimal bactericidal concentration of $2.74 \mu \mathrm{mol} / 1(1.0 \mu \mathrm{g} / \mathrm{ml})$ utilised as a low susceptibility reference isolate. Against these two reference isolates the inhibitory titres of each one hour and nine hour serum sample from the patients who received amoxycillin were determined. Age, physical characteristics, corresponding serum amoxycillin concentrations, and inhibitory titres were submitted to product moment correlation analysis. Where appropriate, confidence limits were calculated by standard methods for binomial proportions.

\section{Results}

Amoxycillin was not detected in any of the serum samples taken before treatment or in any of the samples taken after treatment from the 12 patients given placebo. Correlations between amoxycillin concentrations at one and nine hours and age and physical characteristics of patients given the active drug were weak and did not approach statistical significance. Moreover, interindividual variation in amoxycillin concentrations was much greater in the one hour samples. A weak but statistically significant correlation was found between the concentrations at one and nine hours $(r=0.34 ; p<0.05)$. There were consistent, statistically significant correlations between the amoxycillin concentrations in each one hour and nine hour serum sample and the corresponding inhibitory titres against the low susceptibility reference isolate $(r=0.46$ and $r=0.48$ respectively; $p<0.005)$. Similarly, the corresponding correlation coefficient for the high susceptibility reference isolate was $0.48(\mathrm{p}<0.005)$ using nine hour serum samples but could not be calculated with one hour samples (details available on request).

Against the reference viridans streptococcus isolate with high susceptibility amoxycillin concentrations in all the one and nine hour samples exceeded the minimal bactericidal concentration and the serum inhibitory titres were invariably fourfold or greater. Against the reference isolate with low susceptibility to amoxycillin the concentrations in all one hour samples exceeded the minimal bactericidal concentration (see figure) and serum inhibitory titres were always fourfold or greater. In the nine hour samples, however, amoxycillin concentrations were less than the minimal bactericidal concentration in 18 patients and less than the minimal inhibitory concentra- tion in seven (figure), and in 10 patients serum inhibitory titres were $<2$. The $95 \%$ confidence intervals for the proportions of nine hour serum amoxycillin concentrations equal to or exceeding the minimal bactericidal concentration and minimal inhibitory concentration of the reference isolate with low susceptibility were $34-66 \%$ and $63-68 \%$ respectively. Serum amoxycillin concentrations at one and nine hours showed no obvious relation to preceding food intake.

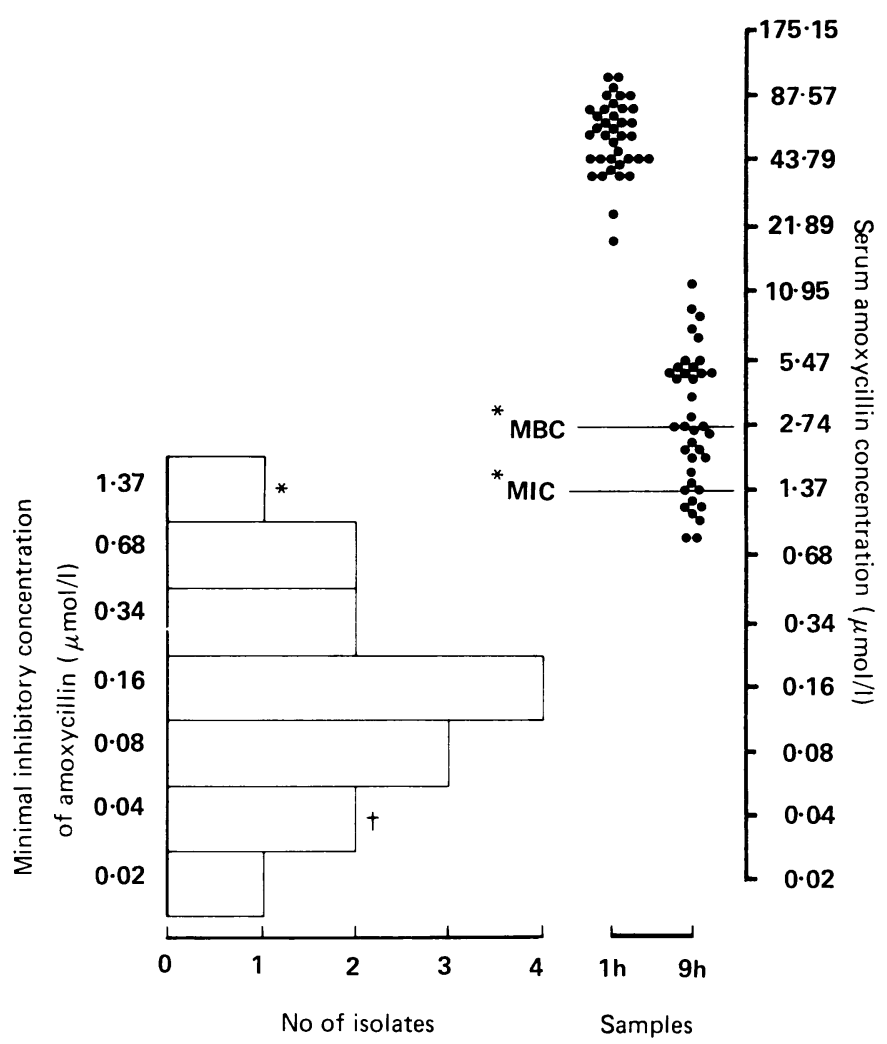

Left: Frequency distribution of minimal inhibitory concentrations of amoxycillin against viridans streptococci $(n=15)$ isolated from patients with infective endocarditis. Right: Serum amoxycillin concentrations in each patient receiving amoxycillin $(n=38) .{ }^{\star}$ and + denote values for reference isolates with low and high susceptibilities to amoxycillin respectively. $\mathrm{MIC}=$ minimal inhibitory concentration, $\mathrm{MBC}=$ minimal bactericidal concentration.

Conversion: SI to traditional units-Amoxycillin: $1 \mu \mathrm{mol} / 1 \approx 0.37 \mu \mathrm{g} / \mathrm{ml}$.

\section{Discussion}

The 15 isolates of viridans streptococci causing endocarditis used in our study were assumed to have originated in the mouth. Thus any simple drug regimen consistently conferring an appropriate period of serum bactericidal activity against all these isolates during and after dentistry might justifiably be advocated as an effective means of providing prophylaxis. The clinically and statistically significant positive correlations between corresponding serum inhibitory titres and amoxycillin concentrations and the failure to detect amoxycillin in samples from subjects taking placebo suggest that the values determined by our bioassay were reliable and valid over a wide range of concentrations. Correlation analysis showed that age and physical characteristics had no important influence on amoxycillin concentrations, but patients with relatively high concentrations at one hour were likely to have correspondingly high concentrations at nine hours.

Experimental streptococcal endocarditis may be prevented even without achieving bactericidal concentrations of circulating amoxycillin so long as the inoculum remains small. ${ }^{4}$ Such protection has been attributed to the prevention of bacterial adherence to endothelium, but complete protection (independent of inoculum size) requires bactericidal concentrations. In one case report the single dose oral amoxycillin regimen failed to prevent Streptococcus milleri endocarditis after dentistry.' Against this particular isolate the 
minimal bactericidal concentration of amoxycillin was $27 \cdot 4 \mu \mathrm{mol} / 1$ $(10.0 \mu \mathrm{g} / \mathrm{ml})$ but the minimal inhibitory concentration was only $0.07 \mu \mathrm{mol} / 1(0.025 \mu \mathrm{g} / \mathrm{ml})$; the failed prophylaxis against this relatively tolerant pathogen was ascribed to persistent exposure to large inocula. From our data even nine hours after taking amoxycillin serum concentrations exceeding the minimal inhibitory concentration $(0.07 \mu \mathrm{mol} / \mathrm{l})$ were likely but bactericidal concentrations $(27 \cdot 4$ $\mu \mathrm{mol} / \mathrm{l}$ ) would not have occurred. Clearly, even if amoxycillin concentrations exceed the minimal inhibitory concentration for prolonged periods failure to maintain bactericidal values may be critical.

Our study suggests that nine hours after a $3 \mathrm{~g}$ dose of oral amoxycillin syrup (eight hours after dentistry) serum is not necessarily bactericidal against relatively resistant pathogenic strains of viridans streptococci in about half of all patients. Hence whenever the possibility of infection with viridans streptococci warrants a second dose of amoxycillin this should not be left till eight hours after the procedure as recommended hitherto. ${ }^{1}$ By repeating the dose after about four hours, however, more effective prophylaxis may be obtained even against relatively resistant species.

We thank the University of Hong Kong dental and medical faculties and Beecham Pharmaceuticals for financial support and facilitating this work. We are also indebted to Professor C E Renson for his helpful advice and encouragement.

\section{References}

1 Shanson DC, Ashford RFU, Singh J. High dose oral amoxycillin for preventing endocarditis. Br Med F 1980;280:460

Oakley C, Somerville W. Prevention of infective endocarditis. Br Hear f 1981;45:233-5.

3 Bayliss $R$, Clarke $C$, Oakley $C$, Somerville $W$, Whiffield AGW. The teeth and infective endocarditis. Br Heart $\mathcal{F}$ 1983;50:506-12.

4 Glauser MP, Bernard JP, Moreillon P, Francioli P. Successful single dose amoxycillin prophylaxis against experimental endocarditis: evidence of two mechanisms of protection. $\mathcal{J}$ Infect Dis 1983;147:568-75

5 Denning DW, Cassidy $M$, Dougall A, Stewart $\mathrm{H}$. Failure of single dose amoxycillin as prophylaxi against endocarditis. BrMed $\mathcal{F}$ 1984;289:1499-500.

(Accepted 30 September 1986)

\title{
Role of vagal neuropathy in the hyponatraemia of alcoholic cirrhosis
}

\author{
G DECAUX，P CAUCHIE，A SOUPART, M KRUGER， F DELWICHE
}

\begin{abstract}
The hyponatraemia common in decompensated cirrhosis arises in part from secretion of antidiuretic hormone attributed to a decrease in effective blood volume. Baroreceptors send inhibitory impulses to the midbrain and hypothalamus through the vagus and glossopharyngeal nerves. Since vagal neuropathy often occurs in chronic alcoholism, this might theoretically contribute to the inappropriate secretion of antidiuretic hormone, which might in turn induce hyponatraemia. In a prospective study including 34 patients with cirrhosis a high incidence of vagal neuropathy was found in the alcoholics $(64 \%)$ and a clear cut increase in the incidence of hyponatraemia in patients with evidence of vagal damage and ascites (seven of eight patients $(88 \%) ; p=0.02)$. Results of a retrospective study of 64 patients with cirrhosis and ascitic decompensation showed hyponatraemia in $17(50 \%)$ of 34 alcoholics but in only four $(13 \%)$ of 30 patients with non-alcoholic disease $(p=0.006)$.

Vagal neuropathy in alcoholic cirrhosis may contribute to the low serum sodium concentrations commonly found in these patients.
\end{abstract}

\footnotetext{
Department of Internal Medicine, University Hospital Erasme, and the Institute of Interdisciplinary Research, School of Medicine, Free University of Brussels, Brussels, Belgium

G DECAUX, MD, PHD, assistant

A SOUPART, MD, assistant

F DELWICHE, MD, assistant
}

University Hospital Saint-Pierre, Free University of Brussels, Brussels, Belgium

P CAUCHIE, MD, assistant, department of internal medicine

M KRUGER, MD, assistant, department of neurology

Correspondence to: Dr G Decaux, Service de Medecine Interne, Hôpital Universitaire Erasme, 808 Route de Lennik, 1070 Bruxelles, Belgium.

\section{Introduction}

The hyponatraemia commonly found in cirrhosis is generally attributed to an excessive secretion of antidiuretic hormone despite hypo-osmolality of the blood. ${ }^{1}$ The classical theory suggests that patients with decompensated disease have a decrease in the "effective" central blood volume resulting in decreased vagal and glossopharyngeal afferent influx to the midbrain and hypothalamus. The decreased afferent neural input is associated with a non-osmotic release of antidiuretic hormone and increased sympathetic activity. ${ }^{23}$ All published studies on hyponatraemia in cirrhosis have disregarded any alcoholic origin of the cirrhosis.

A high incidence of vagal neuropathy in chronic alcoholism has recently been described, ${ }^{4}$ which may have a role in inappropriate secretion of antidiuretic hormone. ${ }^{2}$ We decided to investigate this hypothesis systematically in patients with alcoholic and nonalcoholic cirrhosis and report here our results.

\section{Patients and methods}

We studied prospectively 34 consecutive patients (mean age 50 (SD 8 ) years) with normal renal function and histologically proved liver cirrhosis; 25 were alcoholics and nine had posthepatitic disease. All patients had a serum creatinine concentration below $97 \mu \mathrm{mol} / 1(1 \cdot 1 \mathrm{mg} / 100 \mathrm{ml})$ and a total bilirubin concentration below $50 \mu \mathrm{mol} / 1(2.9 \mathrm{mg} / 100 \mathrm{ml})$. From at least 10 days before the study all patients and controls were medication free and (except for 18 patients with ascites) taking a normal hospital diet providing $50-100 \mathrm{mmol}(\mathrm{mEq})$ sodium daily; patients with ascites received a low salt $\operatorname{diet}(10-20 \mathrm{mmol}$ sodium daily). Intake of water was unrestricted and in all cases exceeded 2 litres a day. All the patients were clinically stable. None had signs of liver encephalopathy, evidence of infection, history of recent gastrointestinal bleeding, or diabetes. The alcoholic patients had not touched alcohol for at least 10 days before the tests of autonomic function.

Subjects were assessed for vagal neuropathy by measuring the heart rate response to standing, ${ }^{5}$ deep breathing, ${ }^{6}$ and atropine. ${ }^{4}$ Normal limits were established by studying an abstinent control population of 34 inpatients of similar age and sex who were free of any disease or medication known to interfere with vagal function. 